\title{
Exposure to Physical Activity Resources by Neighborhood Sociodemographic Characteristics in Copenhagen
}

\author{
Chalida Svastisalee, Jasper Schipperijn, Bjørn E. Hostein, Lisa M. Powell, and Pernille Due
}

\begin{abstract}
Background: To investigate socioeconomic patterning of physical activity resources in Copenhagen. Methods: We used multivariate logistic regression analysis to examine the association between physical activity-supportive resources [public open space (POS), cycling and walking paths, sports facilities, and intersection density] and neighborhood sociodemographic indicators (low education, recent immigrants, children under $15 \mathrm{yr}$, and household income). Results: Neighborhoods with high proportions of residents with low education were most likely to have POS (OR $=2.63 ; \mathrm{CI}: 2.10-3.29)$, paths (OR $=3.60 ; \mathrm{CI}: 2.84-4.56)$ and sports facilities (OR = 5.96; CI: 4.31-8.24). Mid-to-low income areas were less likely to contain POS (OR = 67; CI: $0.49-0.90)$, paths $(\mathrm{OR}=0.36 ; \mathrm{CI}: 0.26-0.50)$, and sports facilities $(\mathrm{OR}=0.48 ; \mathrm{CI}: 0.30-0.77)$. Areas with children were less likely to have connected streets $(\mathrm{OR}=0.51 ; \mathrm{CI}: 0.31-0.83)$ but more likely to have POS $(\mathrm{OR}=1.40 ; \mathrm{CI}$ : 1.15-1.70) and paths ( $\mathrm{OR}=1.52 ; \mathrm{CI}: 1.25-1.85)$. Conclusions: Residents living in areas with high proportions of low education or young children are likely to have high exposure to physical activity resources. Exposure to physical activity resources in Copenhagen may not explain the inequalities in physical activity behavior. Further examination of exposure to built environment resources is warranted.
\end{abstract}

Keywords: built environment, socioeconomic disparity, Europe

Adequate levels of physical activity in combination with a healthy diet, are highly recommended by public health policy to prevent obesity and other chronic diseases. ${ }^{1}$ As there is growing scientific evidence that exposure to physical activity resources [sports facilities, public open space (POS), or transport-supportive paths and streets] is associated with individual levels of physical activity, ${ }^{2-11}$ public health policies also present a unique challenge aimed at local planning boards ${ }^{12-14}$ to ensure living environments support habitual physical activity.

Yet despite public health policy efforts to address the distribution of physical activity resources as part of planning efforts, disparities in individual physical activity by either socioeconomic status ${ }^{15-17}$ or race/ethnicity ${ }^{18-21}$ are well-documented. There has been less emphasis in the literature however, on whether physical activity resources are equitably distributed across neighborhoods, and whether these patterns are characterized by differences in socioeconomic status or racial/ethnic background. Current investigations examining neighborhood-level socioeconomic status and availability of physical activity resources are still emerging and patterns are unclear.

Svastisalee, Hostein, and Due are with the National Institute of Public Health, University of Southern Denmark, Copenhagen, Denmark. Schipperijn is with the Institute of Sports Science and Clinical Biomechanics, University of Southern Denmark, Copenhagen, Denmark. Powell is with the Institute for Health Research and Policy, University of Illinois at Chicago.
Studies conducted on either a city or national level show higher SES neighborhoods have more amenities in POS than lower SES neighborhoods, ${ }^{22}$ while others report no socioeconomic patterning of POS in general ${ }^{23,24}$ or even greater exposure of POS in areas of deprivation. ${ }^{25-27}$ Others examining the relationship between SES and exposure to recreational or sports facilities report that low SES areas having greater exposure to facilities than higher SES neighborhoods, ${ }^{26.28}$ no consistent patterning by $\mathrm{SES},{ }^{29,30}$ or less exposure in low-income areas. ${ }^{24,31-33}$

There are even fewer studies investigating the relationship between neighborhood racial/ethnic distribution and availability of physical activity resources. Most studies, of which all were conducted in the U.S., demonstrate on local and national levels that physical activity facilities, $, 5,24,32$ or sidewalks ${ }^{34}$ are not evenly distributed among neighborhoods with a high proportion of ethnic minorities. In a study on park access, however, Cutts et al ${ }^{35}$ reported areas with a high proportion of Latino or African American residents actually had high access to parks, but children under 18 years of age were underrepresented in areas of high walkability and park density.

To date, examinations of the distribution of physical activity resources by socioeconomic status or race/ ethnicity at an area level are still too few to reveal notable patterns within a European context, with the exception of a few studies conducted in France, ${ }^{29}$ the UK, ${ }^{25}$ Spain, ${ }^{36}$ and the Netherlands. ${ }^{30}$ Furthermore, few studies examined various types of physical activity resources in one study. ${ }^{24,26-28}$ 
Of particular interest is whether the distribution of physical activity resources is socioeconomically patterned in a Scandinavian context, as there tends to be relatively less income inequality. ${ }^{37}$ As a welfare state, income is significantly redistributed through taxation so that higher income earners pay higher taxes, resulting in smaller differences between wealthy and nonwealthy residents. ${ }^{37}$ Further illustration of this leveling may be reflected by the Gini coefficient, which is a widely-used measure of income inequality. ${ }^{38}$ Denmark, for example, has a Gini coefficient of 0.25 , while the United States $(0.41)$ and Australia $(0.35),{ }^{38}$ where a large part of research occurs regarding the impact of exercise environments on physical activity, have greater levels of inequality. Ecological explorations of physical activity environments in Denmark have not been readily published, but are important because they contribute to discussions about policy and health. The purpose of this study was to evaluate whether neighborhood-level socioeconomic and demographic indicators such as education, age and immigration status were associated with exposure to a variety of physical activity resources (urban green space, cycling and walking paths, intersection density, and sports facilities) in the city of Copenhagen, Denmark.

\section{Methods}

\section{Neighborhood Boundaries}

Administrative map boundaries for all neighborhoods in Copenhagen ( $n=400$; population: 518,574 ; area: 88.25 $\left.\mathrm{km}^{2}\right)^{39}$ were supplied by the Danish Map and Cadastre (Danish Map and Cadastre, 2007). Neighborhood units of this study are based on 'rodes,' which are the smallest administrative parcels unique only to Copenhagen, and were previously used for enumeration, taxation, and school allocation. ${ }^{40} \mathrm{On}$ average, the surface area of 1 rode is approximately $0.4 \mathrm{~km}^{2}$, and is still used today as a unit of analysis for statistical purposes by the City. Due to its relatively small size, it is possible to potentially identify individual persons living in a rode. Therefore, 6 rodes with sample populations below 10 were merged with the neighboring rode. In addition, 5 rodes were eliminated due to missing outcome measures because of lack of residents. Thus, a total of 389 out of a possible 400 neighborhoods were available for analysis.

\section{Socioeconomic Data}

Socioeconomic information for 2007 was obtained from Statistics Denmark, provider of national statistics data (Statistics Denmark, 2007). The information produced by Statistics Denmark is based on full population registry data and undergoes consistent monitoring.

We selected socioeconomic variables based on population characteristics demonstrated in the literature to be correlated with having poor access to physical activity resources. The immigration variable is defined as the proportion of foreign-born non-Danish nationals (excluding descendents) living in the neighborhood. The low education variable was defined by the proportion of 16- to 85-year-olds in each neighborhood lacking a high school diploma. The youth variable was defined by the proportion of residents per neighborhood under 15 years of age. While age is not classically defined as a potential risk factor for poor access to physical activity resources, we include age in this analysis because we considered that neighborhoods with a high proportion of children should have greater exposure to parks and playgrounds than areas with lower proportions of children, whereas in the literature, we have found the opposite to be the case. ${ }^{35}$ We used mean percentages as comparative cutpoints for analysis for all socioeconomic indicators. As initial analyses (data not shown) indicated no notable patterning of the physical activity resource exposures at stratified levels of income, we chose in this analysis not to stratify by income level.

\section{Physical Activity Resources}

We selected physical activity resources within the built environment most commonly demonstrated in the literature to be correlated with physical activity in children ${ }^{4}$ and adults, ${ }^{41}$ as well as resources that have been found to be patterned by sociodemographic and/or socioeconomic characteristics. All physical activity resource variables (sports facilities, total POS, ratio of POS per rode, total length of cycling and walking paths, and intersection density) were located on a multilayer topographical map provided by the Danish Map and Cadastre. ${ }^{42}$ Using ArcGIS 9.2 (ESRI, Redmond, CA), we selected all sports facilities (ex. sports centers, tennis courts, swimming pools), and all public urban green space accessible for recreation purposes (ex. parks, playgrounds, open public space, and woodlands) within each rode boundary. As Denmark does not have universal access laws to public open space, allowing full access to all open lands, land used primarily for agricultural purposes are not publically accessible and hence, were not included as a physical activity resource measure. Measures for sports facilities consisted of counts within each neighborhood. Public open space was determined by the proportion of total area by rode area. Total length of walking and cycling paths was calculated in kilometers. Street connectivity, one of the measures used in walkability indices, ${ }^{10}$ is defined as intersection density within each rode. A road network was built, which involved filtering of motorways from the road network, and joining all intersection nodes with at least a 3-way connection. ${ }^{43}$ Intersection density was then calculated as the ratio of intersection nodes by the rode area. ${ }^{10} \mathrm{All}$ of these measures were performed using ArcGIS and exported for'analysis in SAS 9.1 (SAS Institute, Cary, NC, USA). 


\section{Statistical Analyses}

We used 2 different analytical approaches for this study. As many of our physical activity resource measures were continuous variables (ie, ratio of POS per rode area, total length of cycling/walking paths, and intersection density), we examined the association with socioeconomic indicators using linear regression analyses, controlling for population size per rode. Since not all of the rodes contained each of these resources, meaning that there were natural zeros, we also performed natural logarithm and base $^{1 / 3}$ transformations of the outcome variables to obtain heterogeneity of the variances. ${ }^{44-46}$ We employed linear regression analysis separately for each built environment physical activity resource (Proc GLM), simultaneously contralling for differences in neighborhood population size. In addition, as the number of sports facilities were based on counts, with a number of the rodes absent of a sports facility, we also analyzed all physical activity resource variables via logistic regression analyses. In this case, we examined whether neighborhood level socioeconomic indicators were associated with the likelihood of high exposure (characterized as the top 25\%) to: proportion of POS per rode, total length of cycling and walking paths, intersection density, and number of sports facilities. We employed logistic regression analysis separately for each built environment physical activity resource (Proc Logistic), also simultaneously controlling for differences in neighborhood population size. All statistical analyses were performed in SAS 9.1.

For both analytical approaches, we employed backwise deletion from the fully adjusted model in stepwise fashion to retain the most meaningful socioeconomic variables associated with each physical activity resource measure. Covariates with the least statistical significance were manually removed in each step of deletion until the model contained only those significantly associated with each physical activity resource exposure measure. However, as we were unable to conduct an analysis by linear regression on all of our exposure variables consecutively, we used the results of this analysis as a means for comparison with results derived from logistic regression. We noted little difference in the odds ratios (OR) between the unadjusted, fully adjusted, and final models, and thus, we present results from fully adjusted models only. We express the odds ratios transformed from beta estimates derived from logistic regression analysis, but report $\beta$ estimates and transformation to interpretibility $\left(\beta^{\exp }\right)$ from linear regression analysis in text form only.

\section{Results}

In Table 1, we show that among 389 neighborhoods, there were a total of 73 sports facilities, $361 \mathrm{~km}$ of cycling and walking paths and $13 \mathrm{~km}^{2}$ urban green areas located within city boundaries. Overall, socioeconomic characteristics of Copenhagen neighborhoods were comprised of residents that primarily with low proportions of foreignborn individuals (approx 15\%) and equally low proportions of children under 15 years of age (approx 15\%). On average, $22 \%$ of residents did not have a high school diploma, while average individual disposable income in 2006 for Copenhagen was approximately 26,000 Euros.

Table 2 presents results expressed as odds ratios from logistic regression analysis, which mainly shows that depending on the type of physical activity resource, there is spatial patterning according to education, age or income. All models were controlled for population size per rode. In Model 1, where we tested each

Table 1 Neighborhood Characteristics

\begin{tabular}{|c|c|c|c|c|c|}
\hline Variables & $\mathbf{N}$ & Mean & SD & Min & Max \\
\hline Total neighborhoods & 389 & & & & \\
\hline Sports centers & 73 & 0.19 & 0.55 & 0 & 4.00 \\
\hline Cycling and walking paths $(\mathrm{Km})$ & 361 & 0.93 & 1.96 & 0 & 13.86 \\
\hline Total urban green areas $\left(\mathrm{Km}^{2}\right)$ & 13 & 0.03 & 0.09 & 0 & 0.89 \\
\hline Intersection density (nodes/area) & & 128.42 & 78.19 & 0 & 501.38 \\
\hline Ratio of urban green space/rode area & & 0.10 & 0.18 & 0 & 1.25 \\
\hline Population per rode & & 1298.30 & 708.99 & 0 & 4521.00 \\
\hline \% Foreign-born immigrants & & 14.74 & 7.09 & 0 & 48.00 \\
\hline \% Lacking high school diploma & & 22.01 & 9.54 & 0 & 50.00 \\
\hline$\%$ Lnder 15 years of age & & 13.99 & 5.46 & 0 & 33.60 \\
\hline Average disposable individual income (in Euros) & & 25871.97 & 5697.22 & 0 & 46261.08 \\
\hline
\end{tabular}


Table 2 Fully Adjusted Odds Ratios for Physical Activity Resources in Roder (Top 25\%), Per Indicator, By Typet.

\begin{tabular}{|c|c|c|c|c|}
\hline & Mean & SD & OR & $95 \% \mathrm{Cl}$ \\
\hline \multicolumn{5}{|l|}{ Ratio urban green space to rode area } \\
\hline Immigration status (ref low prop) & 14.36 & 7.59 & 1.11 & $0.89,1.39$ \\
\hline Low education (ref low prop) & 24.73 & 11.05 & 2.63 & $2.10,3.29 * * *$ \\
\hline Youth under $15 \mathrm{yr}$ (ref low proportion). & 14.78 & 6.02 & 1.40 & $1.15,1.70^{* * *}$ \\
\hline Euro (ref high) & 24968 & 6486.97 & & \\
\hline Low income & & & 0.72 & $0.52,1.00$ \\
\hline Mid-to-low income & & & 0.67 & $0.49,0.90 * *$ \\
\hline Mid-to-high income & & & 0.81 & $0.62,1.06$ \\
\hline \multicolumn{5}{|l|}{ Cycling and walking paths $(\mathrm{km})$} \\
\hline Immigration status (ref low prop) & 14.19 & 8.09 & 0.92 & $0.73,1.17$ \\
\hline Low education (ref low prop) & 25.27 & 12.49 & 3.60 & $2.84,4.56 * * *$ \\
\hline Youth under 15 yr (ref low proportion) & 14.81 & 6.80 & 1.52 & $1.25,1.85^{* * *}$ \\
\hline Euro (ref high) & 24640.29 & 7716.49 & & \\
\hline Low income & & & 0.60 & $0.43,0.85^{* *}$ \\
\hline Mid-to-low income & & & 0.36 & $0.26,0.50 * * *$ \\
\hline Mid-to-high income & & & 0.68 & $0.52,0.90 * *$ \\
\hline \multicolumn{5}{|l|}{ Intersection density (nodes/area $\mathrm{km}^{2}$ ) } \\
\hline Immigration status (ref low prop) & 14.76 & 6.41 & 0.99 & $0.80,1.21$ \\
\hline Low education (ref low prop) & 21.11 & 7.81 & 0.80 & $0.65,0.98 *$ \\
\hline Youth under 15 yr (ref low proportion) & 13.17 & 4.26 & 0.63 & $0.52,0.76^{* * *}$ \\
\hline Euro (ref high) & 26328.28 & 3703.12 & & \\
\hline Low income & & & 0.96 & $0.71,1.31$ \\
\hline Mid-to-low income & & & 1.17 & $0.89,1.53$ \\
\hline Mid-to-high income & & & 1.09 & $0.84,1.40$ \\
\hline \multicolumn{5}{|l|}{ Counts of sports centers ( 0 vs. 1 or more) } \\
\hline Immigration status (ref low prop) & 15.87 & 9.31 & 0.68 & $0.49,0.93^{*}$ \\
\hline Low education (ref low prop) & 26.81 & 12.40 & 5.96 & $4.31,8.24 * * *$ \\
\hline Youth under 15 yr (ref low proportion) & 15.13 & 6.93 & 0.87 & $0.68,1.12$ \\
\hline Euro (ref high) & 23514.23 & 6852.13 & & \\
\hline Low income & & & 1.94 & $1.22,3.09 * *$ \\
\hline Mid-to-low income & & & 0.48 & $0.30,0.77 * *$ \\
\hline Mid-to-high income & & & 1.43 & $0.96,2.12$ \\
\hline
\end{tabular}

${ }^{t}$ Adjusted for population/rode area.

* Denotes significance at the .05 level; ** denotes significance at the .01 level; *** denotes significance at $<.0001$ level.

Note. Boldface indicates significance.

socioeconomic characteristic singularly, neighborhoods with a high proportion of residents lacking a high school diploma were more likely to have high exposure to public open space $(\mathrm{OR}=2.00)$, cycling and walking paths $(\mathrm{OR}=$ $2.41)$, and sports centers $(\mathrm{OR}=4.25)$ than referent areas, but less likely to have high exposure to interconnected roads $(\mathrm{OR}=0.59)$. Neighborhoods with a high proportion of youth were less likely to have high exposure to highly connected streets $(\mathrm{OR}=0.46)$ compared to the referent. Low-income areas were 2.34 times more likely to have at least one or more sports facilities in the neighborhood, while mid-low income areas were less likely to have 
high exposure to cycling and walking paths $(\mathrm{OR}=0.63)$ than high income referent neighborhoods. In Model 2, where we controlled for all socioeconomic characteristics simultaneously, results still showed neighborhoods with high proportions of residents lacking a high school diploma were more likely to have high exposure to POS $(\mathrm{OR}=1.50)$, cycling and walking paths $(\mathrm{OR}=1.80)$ and sports facilities $(\mathrm{OR}=2.18)$ than referent neighborhoods. In addition, areas with high proportions of mid-to-low income had reduced likelihood of being exposed to cycling and walking paths $(\mathrm{OR}=0.54)$, and sports facilities ( $O R=0.42)$ compared with high income areas. Areas of low income still had high likelihood of exposure to sports facilities $(O R=2.47)$ in Model 2.

Significant findings from linear regression analysis using log-transformed variables for cycling and walking paths indicate in final models, only low education to be associated with exposure to cycling and walking paths $(\beta=0.0508 ; \mathrm{SE}=0.0118 ; P=<0.0001)$, which can be expressed as an increase of $1.05 \mathrm{~km}$ of path exposure for each percent increase in neighborhoods lacking a high school diploma. For intersection density, we noted proportions of foreign born immigrants $(\beta=-0.0093$; $\mathrm{SE}=0.0047 ; P=.0466)$ and youth $(\beta=-0.0179 ; \mathrm{SE}=$ $0.0063 ; P=.0049$ ) to be both negatively associated with the built environment variable, such that a decrease of 0.99 nodes/area was indicated for each percent increase in neighborhoods with either foreign born immigrants or youth. For ratio of POS per rode, none of the socioeconomic variables were significant in final models, nor did we detect any evidence that income was significantly associated with any of the built environment exposure variables in final models. Although findings from linear regression analysis cannot be immediately translatable to results from logistic regression analysis, in general, for cycling/walking paths and intersection density, significant associations corresponded with results from logistic regression analysis. In both methods of analysis, a positive and significant association was noted for the proportion of area low education and cycling and walking paths, while a negative association was noted for the proportion of youth and intersection density.

\section{Discussion}

The results represent the first study to explore the socioeconomic and demographic patterning of physical activity resources in a major city in a Scandinavian country. In general, based on our analyses using logistic regression, we report that neighborhoods with a high proportion of residents lacking a high school diploma, are likely to have more exposure to POS, cycling and walking paths, and I or more sports facilities than areas where residents have higher levels of education. Areas with a high proportion of children under the age of 15 were less likely to have exposure to connected streets. Neighborhoods with a high proportion of mid-to-low income earners were least likely to have high exposure to cycling and walking paths, and sports facilities, while low income areas were most likely to have 1 or more sports facilities. With the exception of income, the direction of these associations parallel results from linear regression analyses, such that in final models, areal low education was positively associated with exposure to cycling and walking paths. Negative associations were noted for intersection density and areal youth and foreign-born immigrants.

\section{Education Status}

First, our findings indicate that public open space, cycling and walking paths, and sports facilities in Copenhagen are readily distributed in areas where residents have low education. Our results are partially consistent with studies conducted in the UK ${ }^{25.27}$ and one study in the U.S., ${ }^{26}$ which indicate greater POS exposure in areas of deprivation. One reason for our findings may be a reflection of concerted efforts by planning and parks and recreation departments in Copenhagen to ensure that green areas are not centralized within the city, but spread out into wedges, to ensure greater surface area of greenspace. ${ }^{47}$ Another difference in findings may suggest influences based on urban planning efforts in Copenhagen to encourage bicycle travel within city boundaries. Second to the Netherlands among countries in Europe with a high degree of bicycle travel, it is estimated that $55 \%$ of residents in Copenhagen travel by bicycle to either work or school on a daily basis. ${ }^{48}$ The high level of bicycle commuting may also be reflected in the relatively low degree of car ownership ( 0.20 cars/person calculated from the data).

Our results also show areas with a high proportion of those lacking a high school diploma were more likely to be exposed to 1 or more sports facilities than areas where residents have higher education. These findings are not in agreement with investigations in the U.S., ${ }^{24.31 .32}$ but generally correspond with studies in Australia ${ }^{28}$ and New Zealand. ${ }^{27} \mathrm{~A}$ study by Giles-Corti and colleagues, ${ }^{28}$ reported a greater exposure to recreational facilities in low SES areas in Perth than high SES neighborhoods, but further indicated due to constraints placed by facility membership, usage among low-income residents was low. Lee and authors, ${ }^{26}$ who reported greater exposure of sports facilities in low-income neighborhoods in Northern California of the U.S., also suggest usage of facilities may be low if there are differences in quality. In our analysis, we were unable to distinguish the difference between pay and nonpay facilities using map information provided by the Danish Map and Cadastre, which listed only large facilities over $2500 \mathrm{~m}^{2}$ which could potentially underreport exposure. Investigating the distribution of sports facilities by type using a more refined method of facility categorization may reveal different results as shown by Billaudeau and colleagues. ${ }^{29}$ As there were relatively few numbers of these large sports facilities $(\mathrm{N}=73)$, it is difficult to determine the overall spatial patterning, except that the majority of these facilities lie outside the city center and historically reflect decisions of 1970s urban planning. ${ }^{49}$ During this particular period, the building of large sports complexes were generally supported and built using city funding. As they are usually built to maximize 
usage and access, they would most likely serve those in high population residential neighborhoods. ${ }^{49}$

\section{Youth}

Second, we demonstrate significant negative association between the proportion of youth per neighborhood in Copenhagen and street connectivity, such that areas with a high proportion of children are less likely to have high exposure to interconnected streets. While we were unable to show a significant association between a high proportion of youth and POS, results from our study partially agree with findings by Cutts et al, ${ }^{35}$ who reported areas in Phoenix, Arizona with a high proportion of children under 18 years of age were under-represented in areas of high walkability and park density. Differences in results could again be attributed to greening policies of the city, or perhaps a reflection of residential choice, as families with young children may choose to live in single family homes, in less densely populated areas with ample green space. ${ }^{50}$ Additionally, the finding that areas with children have reduced exposure to highly connected streets may reflect safety concerns. ${ }^{51-55}$

\section{Immigrant Status}

We were unable to demonstrate using logistic regression analysis, that neighborhoods in Copenhagen with a high proportion of foreign-born immigrants have poor exposure to physical activity resources. In linear regression analyses, we detected a negative relationship between intersection density and the proportion of foreign-born immigrants in the neighborhood. Other studies examining intersection density and walking in minority populations ${ }^{56,57}$ have not reported significant relationships. While findings are not exactly comparable, we note our study results follow the similar patterning of walkability measures as a study conducted in the U.S. among 210 block groups in St. Louis, where Kelly and colleagues ${ }^{34}$ found sidewalks were not equitably distributed in neighborhoods with a high proportion of ethnic minorities.

\section{Income}

In general, we did not find a clear association between income and physical activity resource exposure. We noted reduced likelihood of high exposure to cycling and walking paths and sports facilities with mid-to-low areal income. On the other hand, areas with low-income residents were more likely compared with high income areas, to have high exposure to sports facilities. These findings corroborate previous studies, indicating no clear relationship between cycling and walking paths within POS $^{22}$ or sports facilities ${ }^{29,30}$ and income. We also show using linear regression, there was no significant association between income and any of the built environment physical activity exposure measures. Perhaps the greatest influencing factor on the results may be due to the relatively little income disparity in Denmark, where income is significantly redistributed through taxation so that higher income earners pay higher taxes, resulting in smaller differences between wealthy and nonwealthy residents. ${ }^{37}$

\section{Strengths and Limitations}

Overall strengths of the study include new emerging results relevant for environmental influences on physical activity behavior in a Scandinavian context, which have very different economic and social structures than the U.S. In addition, the application of complete socioeconomic and sociodemographic register data comprise another merit to identify correlations between area-level socioeconomic status and objectively-measured information regarding physical activity resources in the built environment. Similar to other studies, ${ }^{24,27.28}$ we explore a range of physical activity resources to better capture an overall assessment of opportunities for physical activity within a major metropolitan European city.

Several reasons may explain the variability in study results. First, our approach largely focuses on the exposure or availability of physical activity resources, and we recognize that there may be other approaches, such as examination by dasymetric mapping ${ }^{35}$ that may illustrate different patterns of exposure. Second, we suspect that there are methodological differences in defining measures of geographic access and scale. The rode unit of geographical measure for example, while unique only to Copenhagen, is considered to be relatively small in size for the measurement of statistical reporting, ${ }^{40}$ but is still much larger than an average census block in the U.S., the smallest geographical unit for census data. ${ }^{58}$ Third, we were also limited to using physical activity resource measures provided by geographical survey data, and thus bound to adopting categorization schemes of the Danish Map and Cadastre, which does not include specific information such as level of membership (open vs. paying), types of sports serviced (single sport vs. multisport complex), and does not include smaller facilities under $2500 \mathrm{~m}^{2}$. Thus, we recognize that the current collection methods may not be sensitive enough to include smaller facilities, resulting in potential under-reporting of exposure. Fourth, there is indication that data used in this analysis does reflect physical presence based on comparing a sample of the data (data not shown). The quality of data are an important issue and has gained recent recognition in the literature ${ }^{59}$ and should continue to be monitored and even measured in future research. Fifth, unlike other studies examining certain levels of aesthetics and condition $^{29}$ or numbers of amenities ${ }^{22}$ within a given resource, our study was unable to consider indicators of aesthetics or amenities offered by various facilities or urban green space in Copenhagen. Examinations of facility quality would further enrich studies on neighborhood access to physical activity resources, as previous studies in the UK have shown that although low SES areas may have access to more resources, ${ }^{60}$ overall quality or aesthetics may not be the same as in high SES areas. ${ }^{25}$ One other potential source of information bias is that resources in 
neighboring rodes may be used by residents than those supplied within their own neighborhood. However, as our study was unable to further examine the effect of neighboring influences, we acknowledge that such an effect is being currently recognized and methodologically dealt with in the literature. ${ }^{31}$ Furthermore, our study is cross-sectional in approach and thus provides only a static assessment of associations, and cannot address potential causal relations, changes or shifts in neighborhood characteristics. For example, the level of rental status in an area may be a potential driver for shift in neighborhood socioeconomic profile. As a large majority of the city residents $(75 \%)$ do not own their home, neighborhood characteristics are largely determined by rental prices, which may keep overall sociodemographic profiles of an area consistent despite individuals moving in and out of the neighborhood. In addition, the ecological approach of the study means that we are not able to link findings to individual information. The results are limited in terms of explanatory capacity and are unable to make inferences of associations with behavioral outcomes. Future studies would benefit from linking the contextual with individual behavior outcomes as well as with facility usage, as findings from Spain ${ }^{36}$ and the Netherlands ${ }^{30}$ show that exposure does not necessarily indicate usage by individuals. Lastly, our study focuses only on 1 city in Denmark. While examinations of Copenhagen allow us to explore a much more ethnically and socioeconomically diverse population than the rest of the country, study results may be different if the analysis occurred using the entire country, as populations in rural areas of Denmark tend to be more homogeneous, both socioeconomically and ethnically.

\section{Implications}

Although results of our study indicate that exposure to POS, cycling and walking paths, and sporting facilities favor areas with a high proportion of residents not having a high school diploma, our analysis also showed that neighborhoods with a large majority of children have poor exposure to cycling and walking paths. While these findings are in partial agreement with previous studies, the results suggest the need for evidence in other European countries regarding overall socioeconomic patterning of physical activity resources. With regards to policy implementation, results of this study also confirm the need for country-or culturally-appropriate measures of access and socioeconomic disparity. Lastly, more detailed analyses linking the built environment with individual physical activity behavior may provide evidence on the importance of these factors for policymakers.

\section{Conclusion}

We conclude, based on this analysis, that physical activity resources such as POS, cycling and walking paths, and sports facilities were favorably distributed in neighborhoods with low education. However, areas with a high proportion of youth had high exposure to POS and cycling and walking paths, but were under-represented according to interconnected streets. We were unable to detect a clear patterning of physical activity resources by income. Findings partially support other ecological studies conducted outside of the U.S. that show an unclear spatial patterning of physical activity resources by socioeconomic and demographic characteristics at the neighborhood level. ${ }^{22,27-30,34,35}$ The results suggest that within a European context, there may be other unique patterns of neighborhood physical activity resource exposure.

\section{Acknowledgments}

This work was supported in part by The Danish Cancer Society (grant number $002531109310 /$ PP05032), The Danish Health Foundation (grant number 2007B057), The Danish Heart Foundation (grant number 07-4-B195-A1547-22388F), The Danish Graduate School in Public Health Science (GRASPH) at the University of Copenhagen, and The Nordea Foundation.

\section{References}

1. Branca F, Nikogosian H, Lobstein T. The challenge of obesity in the WHO European region and the strategies for response: summary. Copenhagen, Denmark: WHO Regional Office for Europe; 2007.

2. Sallis JF, Prochaska JJ, Taylor WC. A review of correlates of physical activity of children and adolescents. Med Sci Sports Exerc. 2000;32:963-975. PubMed doi:10.1097/00005768-200005000-00014

3. Trost SG, Owen N, Bauman AE, Sallis JF, Brown W. Correlates of adults' participation in physical activity: review and update. Med Sci Sports Exerc. 2002;34:1996-2001. PubMed doi:10.1097/00005768-200205001-01563

4. Davison KK, Lawson CT. Do attributes in the physical environment influence children's physical activity? A review of the literature. Int J Behav Nutr Phys Act. 2006;3:19. PubMed doi:10.1186/1479-5868-3-19

5. Gordon-Larsen P, Nelson MC, Page P, Popkin BM. Inequality in the built environment underlies key health disparities in physical activity and obesity. Pediatrics. 2006;1 17:417-424. PubMed doi: 10.1542/peds. 2005-0058

6. Diez Roux AV, Evenson KR, McGinn AP, et al. Availability of recreational resources and physical activity in adults. Am J Public Health. 2007;97:493-499. PubMed doi:10.2105/ AJPH.2006.087734

7. Bergman P, Grjibovski AM, Hagstromer M, Sallis JF, Sjostrom $M$. The association between health enhancing physical activity and neighbourhood environment among Swedish adults-a population-based cross-sectional study. Int J Behav Nutr Phys Act. 2009;6:8. PubMed doi:10.1186/1479-5868-6-8

8. Sallis JF, Bowles HR, Bauman A, et al. Neighborhood environments and physical activity among adults in 11 countries. Ain J Prev Med. 2009;36:484-490. PubMed doi:10.1016/j.amepre.2009.01.03I

9. Sallis JF, Glanz K. Physical activity and food environments: solutions to the obesity epidemic. Milbank Q. 2009;87:123-154. PubMed doi:10.1111/j.1468$0009.2009 .00550 . x$ 
10. Frank LD, Sallis JF, Saelens BE, et al. The development of a walkability index: application to the Neighborhood Quality of Life Study. Br J Sports Med. 2010; epub ahead of print. PubMed

11. Van Dyck D, Cardon G, Deforche B, Sallis J, Owen N, De Bourdeaudhuij I. Neighborhood SES and walkability are related to physical activity behavior in Belgian adults. Prev Med. 2010;50:S74-S79. PubMed doi:10.1016/j. ypmed.2009.07.027

12. Edwards P, Tsouros A. Promoting physical activity and active living in urban environments: the role of local governments. Copenhagen, Denmark: World Health Organization Europe; 2006 December 2010.

13. Barton H, Grant M, Mitcham C, Tsourou C. Healthy urban planning in European cities. Health Promot lnt. 2009;24(Suppl 1):i91-i99. PubMed doi:10.1093/heapro/ dap059

14. World Health Organization. Health and strategic environmental assessment-background information and report. Copenhagen, Denmark: World Health Organization Europe; 2010 June 8-9, 2009.

15. Borraccino A, Lemma P, Iannotti RJ, et al. Socioeconomic effects on meeting physical activity guidelines: comparisons among 32 countries. Med Sci Sports Exerc. 2009;41:749-756. PubMed doi:10.1249/ MSS.0b013e3181917722

16. Turrell G, Haynes M, Burton NW, et al. Neighborhood disadvantage and physical activity: baseline results from the HABITAT multilevel longitudinal study. Ann Epidemiol. 2010;20:171-181. PubMed doi:10.1016/j. annepidem.2009.11.004

17. Stalsberg R, Pedersen AV. Effects of socioeconomic status on the physical activity in adolescents: a systematic review of the evidence. Scand J Med Sci Sports. 2010;20:368-383. PubMed doi:10.1111/j.1600-0838.2009.01047.x

18. Gordon-Larsen P, McMurray RG, Popkin BM. Adolescent physical activity and inactivity vary by ethnicity: The National Longitudinal Study of Adolescent Health. $J$ Pediatr. 1999;135:301-306. PubMed doi: 10.1016/S00223476(99)70124-1

19. Bolen JC, Rhodes L, Powell-Griner EE, Bland SD, Holtzman D. State-specific prevalence of selected health behaviors, by race and ethnicity - Behavioral Risk Factor Surveillance System, 1997. MMWR CDC Surveill Summ. 2000;49:1-60. PubMed

20. Centers for Disease Control and Prevention. Surveillance summaries, June 28, 2003. MMWR Morb Mortal Wkly Rep. 2003;51:1-64.

21. Afable-Munsuz A, Ponce NA, Rodriguez M, Perez-Stable EJ. Immigrant generation and physical activity among Mexican, Chinese \& Filipino adults in the U.S. Soc Sci Med. 2010;70:1997-2005. PubMed doi:10.1016/j.socscimed.2010.02.026

22. Crawford D, Timperio A, Giles-Corti B, et al. Do features of public open spaces vary according to neighbourhood socio-economic status? Health Place. 2008;14:889-893. PubMed doi:10.1016/j.healthplace.2007.11.002

23. Timperio A, Ball K, Salmon J, Roberts R, Crawford D. Is availability of public open space equitable across areas? Health Place. 2007;13:335-340. PubMed doi:10.1016/j. healthplace.2006.02.003

24. Moore LV, Diez Roux AV, Evenson KR, McGinn AP, Brines SJ. Availability of recreational resources in minority and low socioeconomic status areas. Am J Prev Med. 2008;34:16-22. PubMed doi:10.1016/j. amepre.2007.09.021
25. Ellaway A, Kirk A, Macintyre S, Mutrie N. Nowhere to play? The relationship between the location of outdoor play areas and deprivation in Glasgow. Health Place. 2007;13:557-561. PubMed doi:10.1016/j.health. place. 2006.03.005

26. Lee RE, Cubbin C, Winkleby $M$. Contribution of neighbourhood socioeconomic status and physical activity resources to physical activity among women. $J$ Epide. miol Community Health. 2007;61:882-890. PubMed doi:10.1136/jech.2006.054098

27. Pearce J, Witten K, Hiscock R, Blakely T. Are socially disadvantaged neighbourhoods deprived of health-related community resources? Int J Epidemiol. 2007;36:348-355. PubMed doi:10.1093/ije/dyl267

28. Giles-Corti B, Donovan RJ. Socioeconomic status differences in recreational physical activity levels and real and perceived access to a supportive physical environment. Prev Med. 2002;35:601-611. PubMed doi:10.1006/ pmed.2002.1115

29. Billaudeau N, Oppert JM, Simon C, et al. Investigating disparities in spatial accessibility to and characteristics of sport facilities: direction, strength, and spatial scale of associations with area income. Health Place. 2010; Epub ahead of print. PubMed

30. van Lenthe FJ, Brug J, Mackenbach JP. Neighbourhood inequalities in physical inactivity: the role of neighbourhood attractiveness, proximity to local facilities and safety in the Netherlands. Soc Sci Med. 2005;60:763-775. PubMed doi: $10.1016 /$ j.socscimed 2004.06 .013

31. Estabrooks PA, Lee RE, Gyurcsik NC. Resources for physical activity participation: does availability and accessibility differ by neighborhood socioeconomic status? Ann Behav Med. 2003;25:100-104. PubMed doi:10.1207/ S15324796ABM2502_05

32. Powell LM, Slater S, Chaloupka FJ, Harper D. Availability of physical activity-related facilities and neighborhood demographic and socioeconomic characteristics: a national study. Am J Public Health. 2006;96:1676-1680. PubMed doi: 10.2105/AJPH.2005.065573

33. Sooman A, Macintyre S. Health and perception of the local environment in socially contrasting neighborhoods in Glasgow. Healih Place. 1995; 1:15-26. doi:10.1016/13538292(95)00003-5

34. Kelly CM, Schootman M, Baker EA, Barnidge EK, Lemes $A$. The association of sidewalk walkability and physical disorder with area-level race and poverty. J Epidemiol Community Health. 2007;61:978-983. PubMed doi: $10.1136 /$ jech.2006.054775

35. Cutts BB, Darby KJ, Boone CG, Brewis A. City structure, obesity, and environmental justice: an integrated analysis of physical and social barriers to walkable streets and park access. Soc Sci Med. 2009;69:1314-1322. PubMed doi: 10.1016/j.socscimed.2009.08.020

36. Pascual C, Regidor E, Martinez D, Elisa Calle M. Dominguez V. Socioeconomic environment, availability of sports facilities, and jogging, swimming and gym use. Health Place. 2009;15:553-561. PubMed doi:10.1016/j.healthplace. 2008.08.007

37. Kangas $O$. Relative to what?: crossnational picture of European poverty measured by regional, national and European standards. Eur Soc. 2007;9:119-145. doi:10.1080/14616690601002632

38. Fukuda-Parr S, De Gregorio C, Fu H, et al. Human Health Report 2004: cultural liberty in today's diverse world. New York, USA: United Nations Development Programme; 2004. 
39. Center for Statistics. Population facts and statistics. Copenhagen: City of Copenhagen; 2010.

40. Møller-Jensen L. Assessing spatial aspects of school location-allocation in Copenhagen. Danish Journal of Geography. 1998;98:7I-80 (Geografiske Tidsskrift).

41. Li F, Harmer PA, Cardinal BJ, et al. Built environment, adiposity, and physical activity in adults aged 50-75. Am J Prev Med. 2008;35:38-46. PubMed doi:10.1016/j. amepre.2008.03.021

42. Danish Map and Cadastre. Specifications guide. Copenhagen: Danish Map and Cadastre; 2001:1-176.

43. Smith G, Davey R. Socio-ecological mapping of physical activity behaviours and health outcomes in deprived inner-city communities: geographical information sys. temstechnical report. Stoke on Trent, UK: Staffordshire University; 2008. Report No. version 2.

44. Manning WG. The logged dependent variable, heteroscedasticity, and the retransformation problem. $J$ Health Econ. 1998;17:28.3-295. PubMed doi:10.1016/S01676296(98)00025-3

45. Lachenbruch PA. Analysis of data with excess zeros. Stat Methods Med Res. 2002;11:297-302. PubMed doi:10.1191/0962280202sm289ra

46. Afifi AA, Kotlerman JB, Ettner SL, Cowan M. Methods for improving regression analysis for skewed continuous or counted responses. Annu Rev Public Healih. 2007;28:95-1 I1. PubMed doi:10.1146/annurev.publhealth.28.082206.094100

47. Caspersen O, Konijnendijk C, Olafsson A. Green space planning and land use: an assessment of urban regional and green structure planning in greater Copenhagen. Danish Journal of Geography. 2006;106:7-20 (Geografiske Tidsskrift).

48. City of Copenhagen. Cycle statistics. [website] 2010. Available from:http://www.cycling-embassy.dk.

49. Storm R, Brandt H. Idrcet og sport $i$ den danske oplevIsesфkonomi-mellem forening og forretning. [Physical education and sports in the Danish experience economybetween unions and businesses]. Ist ed. Frederiksberg, Denmark: Imagine; 2008.

50. Andrews FJ. Parental perceptions of residential location: impacts on children's health. Health Place. 2010;16:252258. PubMed doi:10.1016/j.healthplace.2009.10.006
5I. Timperio A, Crawford D, Telford A, Salmon J. Perceptions about the local neighborhood and walking and cycling among children. Prev Med. 2004;38:39-47. PubMed doi:10.1016/j.ypmed.2003.09.026

52. Carver A, Salmon J, Campbell K, Baur L, Garnett S, Crawford D. How do perceptions of local neighborhood relate to adolescents' walking and cycling? Am J Health Promot. 2005;20:139-147. PubMed doi:10.4278/0890$1171-20.2 .139$

53. Carver A, Timperio AF, Crawford DA. Neighborhood road environments and physical activity among youth: the CLAN study. J Urban Heallh. 2008;85:532-544. PubMed doi: 10.1007/s1 1524-008-9284-9

54. Hume C, Timperio A, Salmon J, Carver A, Giles-Corti B, Crawford D. Walking and cycling to school: predictors of increases among children and adolescents. Am $J$ Prev Med. 2009;36:195-200. PubMed doi:10.1016/j. amepre.2008.10.011

55. Panter JR, Jones AP, van Sluijs EM, Griffin SJ. Attitudes, social support and environmental perceptions as predictors of active commuting behaviour in school children. $J$ Epidemiol Community Health. 2010;64:41-48. PubMed doi: 10.1136/jech.2009.086918

56. Lopez RP. Neighborhood risk factors for obesity. Obesity (Silver Spring). 2007;15:2111-2119. PubMed doi:10.1038/oby.2007.251

57. Zenk S, Wilbur J, Wang E, et al. Neighborhood environment and adherence to a walking intervention in African American women. Health Educ Behav. 2009;36:167-181. PubMed doi: $10.1177 / 1090198108321249$

58. U.S. Census Bureau. Geographic areas reference manual (GARM). Available from http://www.census.gov/geo/ www/garm.html

59. Lake AA, Burgoine T, Greenhalgh F, Stamp E, Tyrrell $R$. The foodscape: classification and field validation of secondary data sources. Health Place. 2010;16:666-673. PubMed doi: 10.1016/j.healthplace.2010.02.004

60. Macintyre S, Macdonald L, Ellaway A. Do poorer people have poorer access to local resources and facilities? The distribution of local resources by area deprivation in Glasgow, Scotland. Soc Sci Med. 2008;67:900-914. PubMed doi:10.1016/j.socscimed.2008.05.029 
Copyright of Journal of Physical Activity \& Health is the property of Human Kinetics Publishers, Inc. and its content may not be copied or emailed to multiple sites or posted to a listserv without the copyright holder's express written permission. However, users may print, download, or email articles for individual use. 